\title{
Adult Native Joint Septic Arthritis: A Nine-Year Retrospective Analysis in a Portuguese University Hospital
}

\section{Artrite Séptica de Articulação Nativa em Adultos: Estudo Retrospetivo de Nove Anos num Hospital Universitário Português}

\author{
Ana CIPRIANO $\rrbracket^{1}$, Fábio Videira SANTOS ${ }^{1}$, Rita DIAS ${ }^{2}$, André CARVALHO ${ }^{3}$, Ernestina REIS ${ }^{2 *}$, Cláudia PEREIRA²* \\ Ana Cláudia SANTOS ${ }^{4 *}$, Ricardo SOUSA ${ }^{3 *}$, Miguel Araújo ABREU ${ }^{1 *}$
}

Acta Med Port 2021 Dec;34(12):826-832 - https://doi.org/10.20344/amp.12998

\section{ABSTRACT}

Introduction: Septic arthritis of a native joint represents a medical emergency. Drainage and effective antibiotic treatment are critical to avoid joint destruction and long-term impairment. The aim of this study was to evaluate epidemiological and clinical characteristics of patients with the diagnosis of septic arthritis to help establish local guidelines for empirical antibiotic treatment.

Material and Methods: Retrospective analysis of adult patients admitted at Centro Hospitalar Universitário do Porto from 2009 to 2017 with suspected native joint septic arthritis. Relevant demographics, microbiology findings and respective antibiotic susceptibilities were analysed.

Results: Ninety-seven patients, predominantly males (59.8\%) with a median age of 61 years old were included. The most commonly reported comorbidity associated with septic arthritis was diabetes mellitus $(20.6 \%)$. The knee was the most commonly affected joint (71.1\%). Arthrocentesis was performed in all patients, but only $50.5 \%$ had positive microbial growth in the synovial fluid. Staphylococcus aureus was the most frequently identified microorganism, $86 \%$ of which were methicillin susceptible. Gram-negative bacteria were the causative agent in $15 \%$ of cases. A wide range of empirical antibiotic regimens were prescribed with a combination of vancomycin/ carbapenem being the most common (30.9\%). Analysis of antibiotic susceptibility profiles revealed that amoxicillin/clavulanate would have been appropriate as the initial regimen in $89 \%$ of cases.

Discussion: The main causative pathogen was Staphylococcus aureus, with methicillin resistant Staphylococcus aureus remaining rare. The proportion of Gram-negative bacteria implies that these agents should be covered by empirical treatment, although no case of Pseudomonas infection has been identified. Therefore, antipseudomonal coverage is not necessary in empirical regimens.

Conclusion: Routine coverage of methicillin-resistant Staphylococcus aureus and Pseudomonas aeruginosa is not warranted but must be considered when specific risk factors are found. Amoxicillin/clavulanate can provide adequate antibiotic coverage as an empirical treatment for adult native joint septic arthritis. Its use may allow a reduction in use of broader spectrum antibiotics.

Keywords: Anti-Infective Agents; Antimicrobial Stewardship; Arthritis, Infectious; Joints

\section{RESUMO}

Introdução: A artrite séptica representa uma patologia grave que pode levar à destruição articular e diminuição funcional a longo prazo. Adicionalmente à drenagem articular, uma antibioterapia efetiva é crucial. O objetivo deste estudo consistiu em avaliar as características epidemiológicas e clínicas dos doentes admitidos com diagnóstico de artrite séptica e analisar a terapêutica antimicrobiana, estabelecendo orientações locais de tratamento antibiótico empírico.

Material e Métodos: Análise retrospetiva de doentes adultos admitidos no Centro Hospitalar Universitário do Porto com artrite séptica de articulação nativa de 2009 a 2017. Foram revistos os resultados microbiológicos, os perfis de suscetibilidade aos antimicrobianos e os registos médicos.

Resultados: Dos 97 doentes incluídos, 59,8\% eram do género masculino, com uma idade média de 61 anos. A comorbilidade mais comum foi a diabetes mellitus $(20,6 \%)$. O joelho foi a articulação mais afetada $(71,1 \%)$. Realizou-se artrocentese em todos os doentes, com isolamento microbiano em $50,5 \%$ dos produtos. O Staphylococcus aureus foi o microrganismo mais frequente, sendo sensível à meticilina, em $86 \%$ dos casos. As bactérias Gram-negativo foram o agente causal em $15 \%$ das infeções. A associação do carbapenemo e vancomicina foi a antibioterapia empírica mais comummente iniciada (30,9\%), embora em $89 \%$ dos casos a amoxicilina/ clavulanato teria sido apropriada como regime inicial.

Discussão: O principal agente etiológico foi o Staphylococcus aureus, continuando o Staphylococcus aureus resistente à meticilina a ser um agente raro. A percentagem de bactérias Gram-negativo implica a sua cobertura como terapêutica empírica, embora não tenha havido casos de infeção por Pseudomonas. Por isso, a utilização empírica de um antibiótico com atividade antipseudomónica não é necessária

Conclusão: A cobertura antibiótica de Staphylococcus aureus resistente à meticilina e Pseudomonas não é obrigatória, mas pode ser considerada na presença de alguns fatores de risco específicos. A amoxicilina/clavulanato é uma antibioterapia empírica adequada

1. Serviço de Doenças Infeciosas. Centro Hospitalar Universitário do Porto. Porto. Portugal.

2. Serviço de Medicina Interna. Centro Hospitalar Universitário do Porto. Porto. Portugal.

3. Serviço de Ortopedia. Centro Hospitalar Universitário do Porto. Porto. Portugal.

4. Serviço de Microbiologia. Centro Hospitalar Universitário do Porto. Porto. Portugal.

* GRIP - Grupo de Infeção Osteoarticular do Porto - Porto Osteoarticular Infection Group. Centro Hospitalar Universitário do Porto. Porto. Portugal.

Autor correspondente: Ana Cipriano. anacipriano.infecciologia@chporto.min-saude.pt

Recebido: 23 de outubro de 2019 - Aceite: 20 de maio de 2020 - First published: 21 de setembro de 2021 - Online issue published: 02 de dezembro de 202

Copyright $\odot$ O Ordem dos Médicos 2021 
para a artrite séptica de articulação nativa, permitindo reduzir a utilização inadequada de antibióticos de espectro mais alargado.

Palavras-chave: Anti-Infecciosos; Artrite Infecciosa; Articulações; Gestão de Antimicrobianos

\section{INTRODUCTION}

Acute nongonococcal septic arthritis (SA) is considered a medical/surgical emergency, associated with considerable morbidity and mortality if incorrectly treated. ${ }^{1}$ The annual incidence of SA affecting native joints ranges from 2 to 10 per 100000 habitants in the general population, mainly in Western Europe and North America..$^{2-5}$ The incidence risk is almost ten times increased in patients with rheumatological disease, such as rheumatoid arthritis. ${ }^{2,3,6}$ Other risk factors are diabetes, immunosuppressive therapy, intravenous drug use, skin infection or secondary seeding from distant infection (the occurrence of a primary infection in another anatomical site or organ other than the joint). . $, 7,8^{2}$

The classical clinical presentation of SA includes a history of fever, malaise and acutely painful swollen joint with decrease of articular mobility ${ }^{1,9}$ However, clinical presentation lacks specificity, especially in patients with underlying rheumatic disease. ${ }^{9}$

SA is one of the main differential diagnoses of monoarticular arthritis. Therefore, a prompt identification is crucial because this condition can lead to rapid irreversible joint destruction. ${ }^{1}$ Late diagnosis is thus associated with functional impairment, which is permanent in $40 \%$ of cases and a mortality rate of $10 \%$ to $15 \%{ }^{3,8}$

As clinical findings alone are not able to firmly establish a diagnosis, arthrocentesis will be required in most cases. While waiting for synovial fluid culture results, synovial fluid white blood cell count (WBC) and proportion of polymorphonuclear cells are the best diagnostic tools. ${ }^{10}$

In the presence of other clinical signs of infection, when WBC count exceeds 50000 cells $/ \mathrm{mm}^{3}$ there is a strong probability of SA and patients should be treated empirically for septic arthritis, although a lower value must be considered in immunosuppressed patients or in those who received previous antibiotic treatment. ${ }^{9} \mathrm{~A}$ prompt identification of suspected cases is critical, because this condition can lead to rapid irreversible joint destruction. ${ }^{1}$ Late diagnosis is associated with permanent impairment of joint function in $40 \%$ of cases and a mortality rate of $10 \%-15 \%{ }^{3,8}$

The paradigm of treatment is urgent removal of the pus from the joint (either by needle aspiration or surgically) ${ }^{2}$ and adequate antibiotic therapy. Analysis of synovial fluid can be useful in supporting a suspected diagnosis of septic arthritis while waiting for culture results, but initiation of empirical antibiotic treatment is necessary while cultures are pending.

There are algorithms for the diagnosis and treatment of bacterial septic arthritis and guidelines for management of the hot swollen joint in adults. However, these are mainly based on expert opinion, resulting from lack of welldesigned studies for the empirical antibiotic treatment of SA. ${ }^{11,12}$

The aim of this study was to analyse clinical presentation, epidemiology and antibiotic susceptibility profiles of predominant causative pathogens of SA in our setting, allowing us to develop clinical practice guidelines with better empirical antibiotic therapy.

\section{MATERIAL AND METHODS \\ Study Design}

We conducted a retrospective study of adult patients admitted for suspected native joint septic arthritis at a tertiary care center (Centro Hospitalar Universitário do Porto) from January 2009 to December 2017 (Fig. 1). Cases were identified by reviewing hospital discharge diagnosis codes of infectious arthropathies (ICD-10, v.2017, codes M00.0 'Staphylococcal arthritis and polyarthritis') and associated medical records.

Age and sex demographics and clinical information of selected cases were collected. The incidence of comorbidities and information regarding the etiological study and identification of causative agents were also evaluated.

Medical records of identified cases were assessed to confirm the diagnosis of septic arthritis. Data on medical and orthopedic comorbidities and specific risk factors (namely diabetes mellitus, documented pre-existing joint disease such as osteoarthritis or inflammatory arthritis,

Reviewing hospital discharge diagnosis codes of infectious arthropathies (ICD-10, v.2017, codes M00.0]

Medical records of identified cases were assessed to confirm the diagnosis of septic arthritis, from January 2009 (since electronic medical records available) to December 2017.

Exclusion criteria: age < 18 years-old; SA in prosthetic joint, hospitalization for $\geq 2$ days in the previous 90 days, chemotherapy or home wound care in the previous 30 days, admission from a nursing home or long-term care facility. Also: contaminations, bacteriological samples wrongly labelled as synovial fluid.

Data on medical and orthopedic comorbidities and specific risk factors, namely diabetes mellitus, documented pre-existing joint disease such as osteoarthritis or

inflammatory arthritis, intravenous drug use, joint surgery or intra-articular injection in the previous three months.

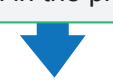

\section{Valid clinical records}

To ensure confidentiality, each case was anonymized by the assignment of a random identification number.

Figure 1 - Data collection protocol used in the study 
intravenous drug use, joint surgery, or intra-articular injection in the previous three months) were collected.

The exclusion criteria were the following: age under 18 years-old; arthritis in prosthetic joint or other surgery related infections with or without orthopedic implants and nosocomial associated factors: hospitalization for more than two days in the 90-day period before admission, chemotherapy or home wound care in the previous three days, admission from a nursing home or long-term care facility. We also excluded: contaminations, bacteriological samples wrongly labelled as synovial fluid. We decided to include patients who had received antibiotic therapy in the last three months, in order to evaluate a proper empirical regimen for all patients.

The study was approved by the Health Ethics Committee of Centro Hospitalar Universitário do Porto [reference number 2019-CE-P007 (11/09/2019)]. Requirement to obtain informed written consent from everyone was waived as the study was limited to the review of existing medical records. To ensure confidentiality, each case was anonymized by the assignment of a random identification number.

\section{Microbial sample collection and analysis}

The standard protocol in the hospital is to perform an arthrocentesis to obtain synovial fluid for culture and leucocyte count with differential analysis before initiation of antibiotic therapy. Synovial liquid was collected and inoculated on Chocolate Agar, MacConkey Agar and Cooked Meat Medium. Strains were identified at the species level using conventional phenotypic tests such as the $\mathrm{VITEK}^{\circledR} \mathrm{MS}$ system (BioMérieux). Antibiotic susceptibility profiles were performed and interpreted according to the EUCAST guidelines (since 2014) and CLSI (formerly NCCLS, until 2013) using automated susceptibility testing, such as VITEK ${ }^{\circledR} 2$ system (BioMérieux), and manual disc diffusion methods when necessary. For each case, the authors reviewed susceptibilities for amoxicillin, amoxicillin/clavulanate, sulfamethoxazole and trimethoprim.

\section{Statistical analysis}

A descriptive statistical analysis was performed using the SPSS software program, version 25 (IBM $^{\circledR}$ SPSS $^{\circledR}$ Inc.). Continuous variables were presented as mean and standard deviation (SD), whereas categorical variables were expressed as frequency (percentage), unless stated otherwise.

\section{RESULTS}

\section{Patient demographics and clinical background}

Of the 169 clinical records that were analysed, 72 did not fulfil the inclusion criteria, and therefore 97 patients were ultimately included. Clinical-demographic characteristics of patients are presented in Table 1. Most patients were male $(59.8 \% ; n=58)$. The mean age was 61.0 years old (DP15.71); (minimum 22, maximum 94).

Most patients had no medical comorbidities (58.8\%; $n=$ $57)$. The most commonly reported comorbidity associated with SA was diabetes mellitus $(20.6 \%, n=20)$ followed by
Table 1 - Age-sex demographics and clinical background of hospitalized adults with native septic arthritis

\begin{tabular}{|c|c|}
\hline Characteristics & $\begin{array}{c}\text { No. of patients } \\
(\%)\end{array}$ \\
\hline [Age (years), mean/median \pm SD] & {$[61 / 63 \pm 15.7]$} \\
\hline $18-39$ years & $10(10.3)$ \\
\hline $40-64$ years & $41(42.3)$ \\
\hline $65-79$ years & $37(38.1)$ \\
\hline$\geq 80$ years & $9(9.3)$ \\
\hline Male gender & $58(59.8)$ \\
\hline \multicolumn{2}{|l|}{ Affected joints } \\
\hline Knee & $69(71.1)$ \\
\hline Hip & $4(4.1)$ \\
\hline Shoulder & $13(13.4)$ \\
\hline Wrist & $2(2.1)$ \\
\hline Ankle & $3(3.1)$ \\
\hline Elbow & $3(3.1)$ \\
\hline Acromioclavicular & $1(1.0)$ \\
\hline Distal interphalangeal joint & $1(1.0)$ \\
\hline \multicolumn{2}{|l|}{ Non-orthopedic comorbidities } \\
\hline Alcohol abuse & $5(5.2)$ \\
\hline Diabetes mellitus & $20(20.6)$ \\
\hline Active malignancy & $3(3.1)$ \\
\hline HIV infection & $7(7.2)$ \\
\hline Immunosuppression ${ }^{\mathrm{b}}$ & $10(10.3)$ \\
\hline \multicolumn{2}{|l|}{ Orthopedic comorbidities } \\
\hline Rheumatoid arthritis & $4(4.1)$ \\
\hline Osteoarthritis & $12(12.4)$ \\
\hline Psoriatic arthritis & $2(2.1)$ \\
\hline Crystal arthropathy & $10(10.3)$ \\
\hline Previous antibiotic (three months) & $16(16.5)$ \\
\hline
\end{tabular}

a Data represent number (percentage) of patients for each variable, except patient age, which is presented as mean \pm SD. ${ }^{b}$ Immunosuppressive drugs were defined as any use of systemic corticosteroids, azathioprine, mycophenolate mofetil, TNF-alpha inhibitor, cyclosporine, cyclophosphamide and/or methotrexate within previous three months. HIV: human immunodeficiency virus

conditions such as human immunodeficiency virus (HIV) $(7.2 \% ; n=7)$. Six patients $(6.2 \%)$ were reported as being intravenous drug users (IVDU).

All cases of septic arthritis involved large joints. The knee was the most affected joint $(71.1 \%, n=69)$, followed by the shoulder $(13.4 \%, n=13)$. Underlying osteoarticular disease was present in $28.9 \%(n=28)$. Of those, two had psoriatic arthritis, four had rheumatoid arthritis, ten had crystal arthropathy, and twelve had idiopathic osteoarthritis. In our cohort, $16.5 \%(n=16)$ of patients had received antibiotic therapy in the three previous months.

At diagnosis, the only clinical sign present in every patient was joint pain. Only $51.5 \%(n=50)$ of patients presented with fever and $47.4 \%(n=46)$ with leucocytosis. Median CRP and ESR was $165 \mathrm{mg} / \mathrm{L}$ (normal range: $0.0-5.0$ ) and $67 \mathrm{~mm} / \mathrm{h}$ (normal range: 0 - 20, men; 0 - 30 women), respectively. As for synovial fluid leucocyte count, it was 
Table 2 - Implicated pathogens in septic arthritis and relevant antimicrobial susceptibility findings

\begin{tabular}{|c|c|c|c|c|c|}
\hline 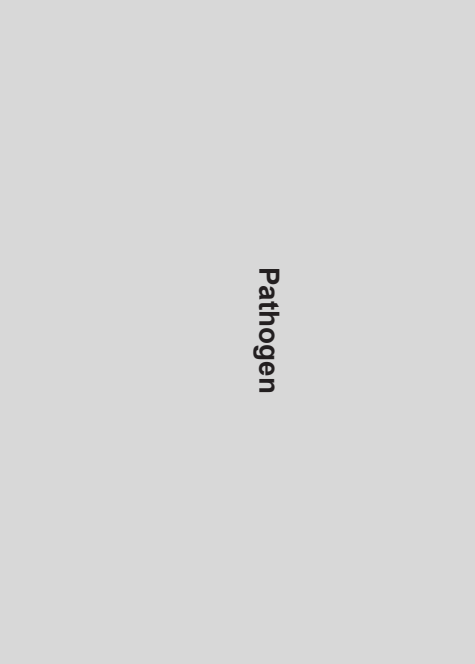 & 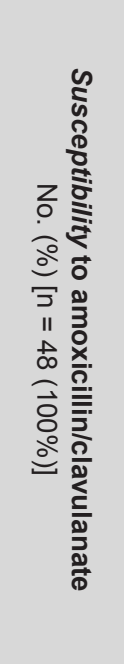 & 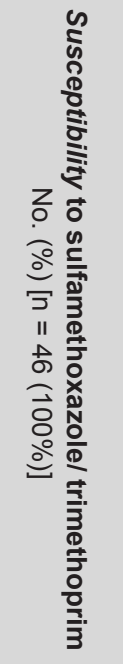 & 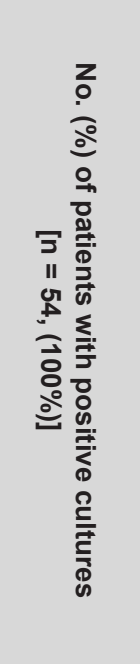 & 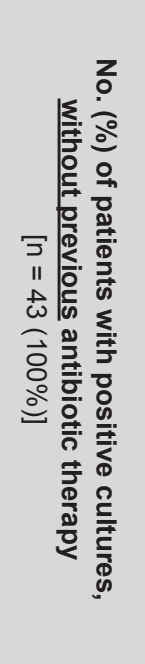 & 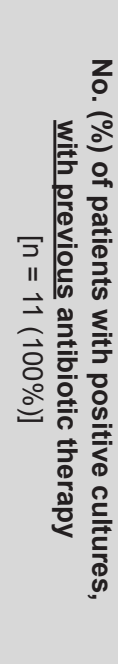 \\
\hline Staphylococcus aureus & $25(52)$ & $29(63)$ & $29(53.7)$ & $22(51.2)$ & 7 \\
\hline MSSA* & $25(52)$ & $25(54)$ & $25(46.3)$ & $9(21)$ & $3(27.2)$ \\
\hline MRSA** & - & $4(8.7)$ & $4(7.4)$ & - & $4(36.4)$ \\
\hline Streptococcus spp. & $9(18.8)$ & $6(13)$ & $9(16.6)$ & $9(20)$ & - \\
\hline Negative coagulase staphylococci & $7(14.6)$ & $5(10.9)$ & $7(12.9)$ & $5(11.6)$ & $2(18.2)$ \\
\hline Gram-negative bacteria & $7(14.6)$ & $6(13)$ & $8(15)$ & $6(14)$ & $2(18.2)$ \\
\hline
\end{tabular}

MSSA*: Methicillin-sensitive Staphylococcus aureus; MRSA**: Methicillin-resistant Staphylococcus aureus

available in only 39 patients, with a median count of 62422 $\times 10^{3} / \mu \mathrm{L}$ (normal range: $<200$ leukocytes/ $\mu \mathrm{L}$ ).

\section{Microbiological etiology of native SA}

The agent was successfully identified in $55.7 \%(n=54)$ of SA cases. The isolated causative pathogens are presented in Table 2.

Arthrocentesis was performed in all patients, with $50.5 \%$ $(n=49)$ having positive microbial growth. Blood cultures were performed in $47.4 \%(n=46)$ of patients and of those $26.1 \%(n=12)$ were positive.

In seven cases, blood culture and synovial aspirate results were concordant. In five cases the agent was only found in blood cultures. Staphylococcus aureus (53.7\%; $\mathrm{n}=29$ ) was the most frequently identified microorganism, with $86.2 \%(n=25)$ being methicillin-susceptible Staphylococcus aureus (MSSA) and four being methicillin resistant (13.8\%). All patients with MRSA received antibiotic treatment during the preceding three months.

Streptococcus spp. were isolated in nine patients $(16.7 \%)$, and coagulase negative Staphylococci isolated in seven patients $(12.9 \%)$. All coagulase negative Staphyloccoci were susceptible to oxacillin and all Streptococcus spp. were susceptible to penicillin.

Gram-negative bacteria were the causative agent in $15 \%(n=8)$ of cases. The most common gram-negative bacteria isolated was Escherichia coli $(75 \% ; n=6)$.

Pseudomonas aeruginosa was not isolated in our cohort. There were no cases of Neisseria gonorrhoeae or $\mathrm{My}$ cobacterium spp. infections diagnosed.
Synovial fluid was sterile in $50 \%$ of patients. However, the presumptive SA diagnosis was assumed based on clinical complaints or arthrocentesis results. Regardless of no

Table 3 - Empirical antibiotic regimens prescribed during the study period

\begin{tabular}{lc}
\hline Empirical antibiotic therapy & $\mathbf{n}(\%)$ \\
\hline Vancomycin + Imipenem & $29(29.0)$ \\
Vancomycin & $15(15.5)$ \\
Imipenem & $9(9.3)$ \\
Ertapenem & $8(8.2)$ \\
Vancomycin + Piperacillin/Tazobactam & $5(5.2)$ \\
Vancomycin + Ceftriaxone & $5(5.2)$ \\
Amoxicillin/Clavulanic Acid & $5(5.2)$ \\
Piperacillin/tazobactam & $3(3.1)$ \\
Flucloxacillin & $3(3.1)$ \\
Clindamycin & $2(2.1)$ \\
Ceftriaxone & $2(2.1)$ \\
Ceftazidime & $1(1.0)$ \\
Ciprofloxacin & $1(1.0)$ \\
Linezolid + Imipenem & $1(1.0)$ \\
Vancomycin + Cefepime & $1(1.0)$ \\
Linezolid + Meropenem & $1(1.0)$ \\
Cefazolin & $1(1.0)$ \\
Ciprofloxacin + Clindamycin & $1(1.0)$ \\
Vancomycin + Meropenem + Clindamycin & $1(1.0)$ \\
Lack of information & $3(3.1)$ \\
\hline
\end{tabular}


microbiological isolation in synovial fluid, an elevated leucocyte count was found in 17 patients, and in five patients, blood cultures were positive with possible agents of SA.

\section{Empirical treatment and antibiotic susceptibility}

Regarding empirical antibiotic therapy, antibiotics prescribed during the study period are presented in Table 3. Carbapenem plus vancomycin $(30.9 \% ; n=30)$ was the most frequently used empirical antibiotic combination. Carbapenems were used as first choice in terms of empirical treatment regimen in $51 \%(n=49)$ cases and vancomycin in $58.3 \%(n=56)$. After microbiological identification and antibiogram availability, initial therapeutic regimens were adjusted in $74.4 \%(n=73)$ cases.

After analysing antibiotic susceptibility profiles, we found that amoxicillin/clavulanate would have been appropriate as the initial empirical regimen in $89 \%(n=48)$ of cases. Sulfamethoxazole/trimethoprim appears as a valid alternative to consider in patients with beta-lactam allergy as it would have been effective in $85 \%(n=46)$ of cases. All five patients in which the isolated microorganism was resistant to amoxicillin/clavulanate had received antibiotic therapy in the prior three months. Four out of these five patients had microbiological susceptibility to sulfamethoxazole and trimethoprim.

\section{DISCUSSION}

Acute SA is an uncommon disease. Therefore, information concerning the epidemiology of septic arthritis is limited. Most of the published reports are from retrospective cohort studies such as this one. Although there are retrospective studies on the epidemiology and clinical presentation of AS in Portugal, ${ }^{13,14}$ to the best of our knowledge this is the first Portuguese study that evaluates the adequacy of the empirical antibiotic regimens with the microbiological isolates and the antimicrobial susceptibility patterns.

As in other reports, the most commonly involved joints were the knee followed by the shoulder.,11,15,16 The clinical findings revealed that only half of patients presented with fever, which highlights that the absence of fever does not exclude this condition. Most cases undergo diagnostic arthrocentesis for culture but also leucocyte count and crystal arthropathy investigation.

Although SA will have a high bacterial load and synovial fluid cultures will be positive, there are confounding factors such as previous antibiotic therapy that may preclude accurate microbial identification. Newman et al proposed this currently accepted definition for SA: (1) isolation of a pathogenic organism from an affected joint; (2) isolation of a pathogenic organism from another source in the setting of a hot red joint raising the suspicion of sepsis; (3) typical clinical features and turbid joint fluid in the presence of previous antibiotic treatment; and (4) post-mortem or pathological features suggestive of SA..$^{1,10}$

In all age groups, regardless of risk factors, the most frequent causative organism was Staphylococcus aureus followed by Streptococcus spp. ${ }^{7,11,14,17}$ Although other micro- organisms (e.g.: Brucella spp., Mycobacterium tuberculosis) may be found in certain contexts. ${ }^{7,15}$

We found concordant results in our cohort, with Staphylococcus aureus being the most frequently recovered microorganism. Streptococci species usually represent the second most common agent of SA, although it is considered a rare agent. ${ }^{17,18}$ In this analysis, Streptococcus spp. was the causative agent in $16.6 \%$ of all SA. The small number of isolates makes it hard to draw conclusions about the most frequent species in our cohort. Coagulase negative staphylococci were isolated in $12.9 \%$ of patients. It is considered a rare agent, being mostly associated with older patients, joint injection site infections, prosthesis infections and immunocompromised host infections. , $^{2,18}$

Gram-negative bacteria (GNB) are traditionally considered an uncommon cause of SA in native joints. ${ }^{1}$ They are much more commonly found in nosocomial or health carerelated infections such as prosthetic joint infection (PJI). ${ }^{19}$ In our cohort Escherichia coli was the most commonly isolated GNB and no Pseudomonas aeruginosa were found.

The proportion of culture negative cases found in this study is probably explained by the fact that, given the inherent high risk of not treating a real SA, most surgeons choose to act accordingly in suspicious cases even if postoperative microbiological findings do not fully support the initial presumptive diagnosis.

Detailed analysis of antibiotic susceptibility patterns in our cohort shows interesting findings. Although $S$. aureus is by far the most common isolate, the methicillin-resistant Staphylococcus aureus (MRSA) proportion remains low in our setting which is in accordance with other European results, where MRSA in community-onset SA, was isolated in only $6 \%-8 \%$ of cases. ${ }^{15,20,21}$ A French cohort showed no important changes in the prevalence of MRSA SA during a three decade period. ${ }^{14}$ In contrast, community-acquired MRSA infections in the USA seems to be significantly higher. ${ }^{22,23}$ In this study specifically, SA due to MRSA remained rare, corresponding to $7 \%(n=4 / 54)$ of all microbiological documented infections and $14 \%(n=4 / 29)$ of $S$. aureus infections.

As such, and in contrast to American recommendations, where results suggest that antibiotics with activity against MRSA should be included in the empirical treatment of SA, ${ }^{23}$ our study suggests that this coverage is usually not necessary. The exception may be those patients who received antibiotics during the preceding three months, since in our cohort all isolated MRSA cases had this risk factor. Evaluation of SA in IVDUs showed that MSSA remained the leading aetiological agent. ${ }^{15,24,25}$ However, the small number of IVDUs in our study prevent us from drawing conclusions on the relevance of our findings to this group.

In terms of Gram-negative coverage, our results suggest Gram-negative bacteria must be considered when selecting empirical antibiotics as they were responsible for a significant proportion of cases. However, there is no need for an anti-pseudomonal antibiotic in the case of native joints $\mathrm{SA}$ in our setting. A similar conclusion was achieved by 
Table 4 -Antimicrobial susceptibility profiles of isolated causative pathogens

\begin{tabular}{lcc}
\hline Empirical antibiotic therapy & Susceptibility, $\mathrm{n}(\%)$ & Resistance, $\mathrm{n}(\%)$ \\
\hline Amoxicillin/Clavulanic Acid & $48(88.9)$ & $6(11.1)$ \\
Sulfamethoxazole and Trimethoprim & $46(85.1)$ & $8(14.9)$ \\
\hline
\end{tabular}

Clerc et al in a ten year review of adult septic native arthritis in Switzerland. ${ }^{11}$

This study has some limitations. Its retrospective design makes it impossible to gain a precise description of the initial clinical presentation and a meticulous review of some risk factors was not possible. The small size of our sample limits the interpretation of results and extrapolation of the data to larger populations as well as subgroup analysis in patients with specific comorbidities such as diabetes mellitus, HIV, IVDU and rheumatoid arthritis. Nevertheless, the findings suggest there may be unnecessary use of broaderspectrum antibiotics in an infection acquired in our community setting, with an excessively broad coverage for MRSA and multidrug resistant gram-negative bacteria.

These results show the importance of developing local antibiotic prescribing guidelines and the continuous monitoring of epidemiological data. Furthermore, it emphasizes the importance of implementing a stewardship program.

According to our local epidemiology (Table 4), the authors consider that amoxicillin/clavulanate would be adequate for empirical coverage of native joint SA in patients without history of recent antibiotic treatment, allowing reduction in use of broader-spectrum antibiotics. As an alternative in patients with $\beta$-lactam allergy, the authors propose trimethoprim/sulfamethoxazole as an appropriate option. Our data suggests that some risk factors, such as previous antibiotic therapy, must be considered and may force different empirical antibiotic choice(s) when planning a therapeutic approach in patients with SA.

\section{CONCLUSION}

In our institution, amoxicillin/clavulanate is an adequate first-line empirical antibiotic for native joint septic arthritis. Routine coverage of MRSA and Pseudomonas aeruginosa is not warranted but must be considered when specific risk factors such as previous antimicrobial treatment are found. The authors suggest these recommendations may also apply to other Portuguese hospitals, that may likely share similar epidemiology, although this would require larger collaborative multicentre studies to confirm it and lead to appropriate national recommendations.

\section{REFERENCES}

1. Mathews CJ, Weston VC, Jones A, Field M, Coakley G. Bacterial septic arthritis in adults. Lancet. 2010;375:846-55.

2. Ross JJ. Septic arthritis of native joints. Infect Dis Clin North Am. 2017;31:203-18.

3. Shirtliff ME, Mader JT. Acute septic arthritis. Clin Microbiol Ver. 2002;15:527.

4. García-Arias M, Balsa A, Mola EM. Best practice \& research clinical rheumatology septic arthritis. Best Pract Res Clin Rheumatol. 2011;25:407-21.

\section{AUTHORS CONTRIBUTION}

AC: Data acquisition, analysis and interpretation; draft of the paper; approval of the final version.

FVS: Data acquisition, analysis and interpretation; draft and critical review of the paper; approval of the final version.

$\mathrm{RD}, \mathrm{AC}$ : Data acquisition; draft of the paper; approval of the final version.

ER: Draft of the paper; critical review; approval of the final version.

CP: Critical review of the paper; approval of the final version.

ACS: Data collection and interpretation; critical review of the paper; approval of the final version.

RS: Data interpretation; critical review of the paper; approval of the final version.

MAA: Draft of the paper; data interpretation; critical review of the manuscript; approval of the final version.

All authors read and approved the final manuscript.

\section{ACKNOWLEDGEMENTS}

The authors would like to thank Robert Ford, for his helpful review of the English language content of this article.

\section{PROTECTION OF HUMANS AND ANIMALS}

The authors declare that the procedures were followed according to the regulations established by the Clinical Research and Ethics Committee and to the Helsinki Declaration of the World Medical Association updated in 2013.

\section{DATA CONFIDENTIALITY}

The authors declare having followed the protocols in use at their working center regarding patients' data publication.

\section{COMPETING INTERESTS}

All authors report no conflicts of interest.

\section{FUNDING SOURCES}

This research received no specific grant from any funding agency in the public, commercial, or not-for-profit sectors.

5. Galloway JB, Hyrich KL, Mercer LK, Dixon W, Ustianowski A, Helbert $M$, et al. Risk of septic arthritis in patients with rheumatoid arthritis and the effect of anti-TNF therapy: results from the British Society for Rheumatology Biologics Register. Ann Rheum Dis. 2011;70:1810-4.

6. Cooper C, Cawley MI. Bacterial arthritis in an English health district: a 10 year review. Ann Rheum Dis. 1986;45:458-63.

7. Gupta MN, Sturrock RD, Field M. A prospective 2-year study of 75 patients with adult-onset septic arthritis. Rheumatology. 2001;40:24-30.

8. Margaretten ME, Kohlwes J, Moore D, Bent S. Does this adult patient 
have septic arthritis? JAMA. 2007:297:1478-88.

9. Li SF, Cassidy C, Chang C, Gharib S, Torres J. Diagnostic utility of laboratory tests in septic arthritis. Emerg Med J. 2007:24:75-7.

10. Clerc O, Prod'hom G, Greub G, Zanetti G, Senn L. Adult native septic arthritis: a review of 10 years of experience and lessons for empirical antibiotic therapy. J Antimicrob Chemother. 2011;66:1168-73.

11. Coakley G, Mathews C, Field M, Jones A, Kingsley G, Walker D, et al. BSR \& BHPR, BOA, RCGP and BSAC guidelines for management of the hot swollen joint in adults. Rheumatology. 2006;45:1039-41.

12. Madruga Dias J, Costa MM, Pereira da Silva JA, Viana de Queiroz M. Septic arthritis: patients with or without isolated infectious agents have similar characteristics. Infection. 2014;42:385-91.

13. Rego de Figueiredo I, Vieira Alves R, Guerreiro Castro S, Antunes A, Gruner H, Panarra A. Septic arthritis incidence and risk factors: a 5-year cross-sectional study. Infect Dis. 2019;51:635-7.

14. Dubost JJ, Couderc M, Tatar Z, Tournadre A, Lopes J, Mathieu S, et al. Three-decade trends in the distribution of organisms causing septic arthritis in native joints: single-center study of 374 cases. Jt Bone Spine. 2014;81:438-4

15. Lotz H, Strahm C, Zdravkovic V, Jost B, Albrich W. Septic arthritis due to streptococci and enterococci in native joints: a 13 year retrospective study. Infection. 2019;47:761-70.

16. Newman JH. Review of septic arthritis throughout the antibiotic era. Ann Rheum Dis. 1976;35:198-205.
17. Helito C, Noffs G, Pecora J, Gobbi R, Tirico L, Lima A, et al. Epidemiology of septic arthritis of the knee at Hospital das Clinicas, Universidade de Sao Paulo. Braz J infect Dis. 2014:18:28-33

18. Sousa R, Pereira A, Massada M, da Silva M, Lemos R, Costa e Castro J. Empirical antibiotic therapy in prosthetic joint infections. Acta Orthop Belg. 2010;76:254-9.

19. Murillo O, Gomez-Junyent J, Grau I, Ribera A, Cabrera C, Pedrero S, et al. Clinical findings of bacteremic septic arthritis according to the site of acquisition: the overlap between health care-related and communityand nosocomial-acquired cases. Eur J Int Med. 2016;28:38-42.

20. Gupta MN, Sturrock RD, Field M. Prospective comparative study of patients with culture proven and high suspicion of adult onset septic arthritis. Ann Rheum Dis. 2003;62:327-31.

21. Frazee $B$, Fee $C$, Lambert L. How common is MRSA in adult septic arthritis? Ann Emerg Med. 2009;54:695-700.

22. Fridkin S, Hageman J, Morrison M, Sanza L, Como-Sabetti K, Jernigan $\mathrm{J}$, et al. Methicillin-resistant Staphylococcus aureus disease in three communities. N Engl J Med. 2005;352:1436-44.

23. Brancos M, Peris P, Miro J, Monegal A, Gatell J, Mallolas, et al. Septic arthritis in heroin addicts. Seminars Arthritis Rheum. 1991;21:81-7.

24. Al-Nammari S, Bobak $P$, Venkatesh $R$. Methicillin resistant Staphylococcus aureus versus methicillin sensitive Staphylococcus aureus adult haematogenous septic arthritis. Arch Orthop Trauma Surg. 2007; $127: 537-42$. 